\title{
Reference soil condition for intensity prediction equations derived from seismological and geophysical data at seismic stations
}

\author{
Francesco Panzera • Paolo Bergamo • Donat Fäh
}

Received: 2 December 2019 / Accepted: 14 October 2020 /Published online: 21 October 2020

(C) The Author(s) 2020

\begin{abstract}
In 2011, an amplification map achieved by macroseismic information was developed for Switzerland using the collection of macroseismic intensity observations of past earthquakes. For each village, a $\Delta \mathrm{Im}$ was first derived, which reflects the difference between observed and expected macroseismic intensities from a region-specific intensity prediction equation. The $\Delta I m$ values are then grouped into geological/tectonic classes, which are then presented in the macroseismic amplification map. Both, the intensity prediction equation and the macroseismic amplification map are referenced to the same reference soil condition which so far was only roughly estimated. This reference soil condition is assessed in this contribution using geophysical and seismological data collected by the Swiss Seismological Service. Geophysical data consist of shear-wave velocity profiles measured at the seismic stations and earthquake recordings, used to retrieve empirical amplification functions at the sensor locations. Amplification functions are referenced to a generic rock profile (Swiss reference rock condition) that is well defined, and it is used for the national seismic hazard maps. Macroseismic amplification factors $A f$, derived from empirical amplification functions, are assigned to each seismic station using
\end{abstract}

Electronic supplementary material The online version of this article (https://doi.org/10.1007/s10950-020-09962-z) contains supplementary material, which is available to authorized users.

F. Panzera $(\bowtie) \cdot$ P. Bergamo $\cdot$ D. Fäh

Swiss Seismological Service, ETH, Zurich, Switzerland

e-mail: francesco.panzera@sed.ethz.ch ground motion to intensity conversions. We then assess the factors $d \Delta f$ defined as the difference between $A f$ and $\Delta I m$. The factor $d \Delta f$ accounts for the difference between the reference soil condition for the intensity prediction equation and the Swiss reference rock. We finally analysed relationships between $A f$ and proxies for shear-wave velocity profiles in terms of average shearwave velocity over defined depth ranges, such as $V_{S, 30}$, providing an estimate of the reference shear velocity for the intensity prediction equation and macroseismic amplification map. This study allows linking macroseismic intensity observations with experimental geophysical data, highlighting a good correspondence within the uncertainty range of macroseismic observations. However, statistical significance tests point out that the seismic stations are not evenly distributed among the various geological-tectonic classes of the macroseismic amplification map and its revision could be planned merging classes with similar behaviour or by defining a new classification scheme.

Keywords Macroseismic intensity - Amplification function $\cdot$ Site proxies $\cdot$ Soil classification

\section{Introduction}

Site-specific seismic hazard assessment requires an estimate of site effects, quantifying frequency-dependent amplification due to geological settings (e.g. Roten et al. 2008; Panzera et al. 2016; Michel et al. 2017). In urban areas struck by earthquakes, an alternative method to 
identify amplification zones consists in the use of macroseismic observations (e.g. Carlino et al. 2010; Sbarra et al. 2012; Panzera et al. 2018). In few cases, this approach was also applied at the national level (e.g. Sousa and Oliveira 1996; Fäh et al. 2011). Although such national macroseismic amplification maps allow detecting the average behaviour at the regional scale, they are not applicable locally (Pettenati et al., 2018).

A macroseismic amplification map for Switzerland (Fig. 1) was developed from the collection of macroseismic intensity observations of past earthquakes and taking into account a set of geological-tectonic classes (Kaestli and Fäh 2006; Fäh et al. 2011). The map is presented in terms of $\Delta I m$, which is the average of the difference between observed and expected macroseismic intensities from a region-specific intensity prediction equation for each geological-tectonic class (Fäh et al. 2011). Both, the intensity prediction equation and the macroseismic amplification map are referenced to the same reference soil condition which was so far only estimated by expert opinion. The macroseismic amplification map for Switzerland is implemented in the Swiss Seismological Service (SED) shake map tool (Cauzzi et al. 2015) to account for site effects at the national scale.

Geophysical and seismological data collected by SED in the framework of different national projects are used here to check and validate the macroseismic amplification map. The geophysical data consist of shear-wave velocity profiles measured at seismic stations (Fäh et al. 2009; Michel et al. 2014; Poggi et al. 2017; Hobiger et al. 2017) using passive and/or active seismic methods. As for seismological data, earthquake recordings are used to retrieve empirical amplification functions at the sensor locations using the spectral modelling method (Edwards et al. 2013). Amplification functions are referenced to a generic rock profile (Swiss reference rock condition) that is well defined (Poggi et al. 2011). The national seismic hazard maps (Wiemer et al. 2016) refer to this generic rock profile. The elastic and the anelastic Fourier amplification functions are converted to pseudo-spectral acceleration (PSA) amplification functions resorting to random vibration theory (SMSIM code - Boore, 2003).

Using these datasets, we investigate the reference soil conditions of the regional intensity prediction equation and the related macroseismic amplification map. Such information is needed to compare probabilistic seismic hazard assessment in ground motion on a well-defined reference rock profile with that for macroseismic intensity.

\section{Macroseismic amplification map}

Macroseismic observations (intensity data points (IDP)) are routinely collected by SED after felt events. The macroseismic data are validated and stored in a dedicated database. This database also comprises reports and macroseismic data points from historical events. The macroseismic intensity dataset includes around 35,000 intensity assignments collected from 17,000 settlements in Switzerland and for 720 earthquakes since 1850 (Kaestli and Fäh 2006), as well as macroseismic data for the time before 1850 for all events that reached EMS98 intensity VI. This macroseismic dataset was used for the compilation of the EMS-98 intensity amplification map of Switzerland (Fig. 1). The macroseismic amplification factors are defined relative to a macroseismic intensity prediction equation and calibrated on a set of geological soil classes as documented in Fäh et al. (2011). The mapped values refer to a soil reference condition that is different to the Swiss reference rock $\left(V_{S, 30}=1105 \mathrm{~m} / \mathrm{s}\right)$ proposed by Poggi et al. (2011) and used in the calculation of the Swiss seismic hazard (Wiemer et al. 2016). This should be accounted for by a constant correction term which, as proposed by Fäh et al. (2011), is about $1 / 2$ intensity units (namely 0.47 ). Such correction allows the necessary adjustment to the Swiss reference rock condition.

The IDP were grouped into soil classes defined by a combination of geological and tectonic characteristics, drawn from the geological map of Switzerland 1:500,000 (Swisstopo 2005). Median $\Delta I m$ were computed for the defined geological soil and rock classes. The resulting $\Delta I m$ range between -0.31 (in the Swiss Alps) and +1.05 intensity units (in the Basel region and in the alluvium-filled alpine basins). The map is delivered in vector format whose polygons enclose areas with equal macroseismic amplification factor. For polygons without an assignment, the amplification was defined as 'unknown'. This macroseismic amplification map was implemented in the ShakeMap tool (USGS code as described in Wald et al. 2005) at SED and tested in combination with the Swiss stochastic ground motion prediction equation, in the sense that we can reproduce at the national scale the ground shaking scenario of the strong historical earthquakes in Switzerland (Cauzzi et al. 2015). Reference soil conditions and uncertainties related to these amplifications were never assessed thoroughly so far, but this is a key issue when comparing seismic hazard estimated in macroseismic intensity with 


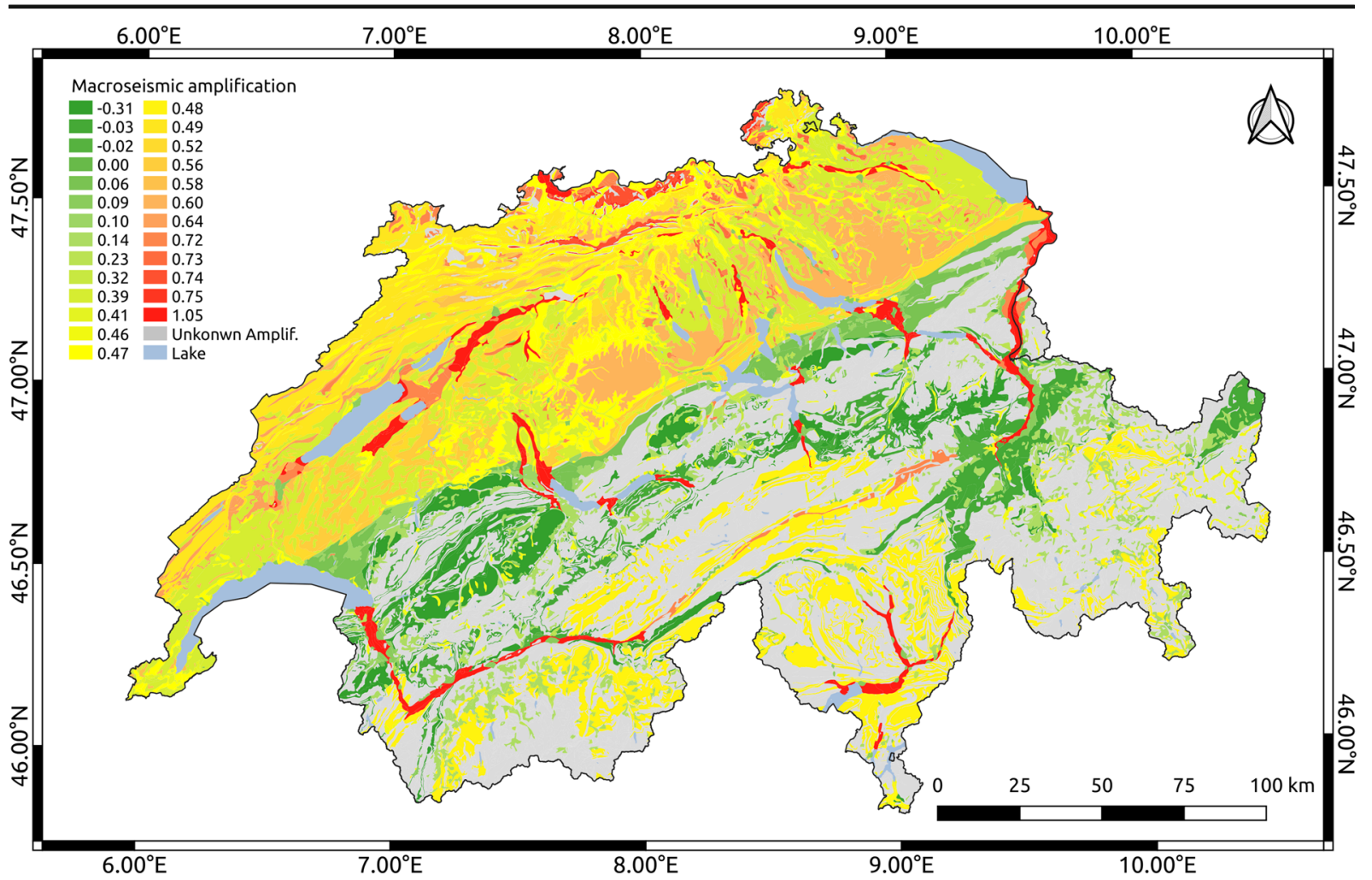

Fig. 1 Site amplification for Switzerland obtained from the analysis of macroseismic data (modified from Fäh et al. 2011)

the one in ground motion. Macroseismic information can also be used in support to regional studies for the identification of areas of anomalous seismic response (e.g. Fäh et al. 2011). Due to the large uncertainty, however, this information should always be complemented with other kind of observations at the local scale.

\section{Seismic site response observed at seismic stations}

3.1 Soil class categorisation and empirical amplification functions

The national seismic networks of Switzerland (Fig. 2) comprise almost 200 permanent stations equipped with accelerometers and/or with velocimeters (strong motion-SSMNet and broadband-SDSNet). In this study, stations in tunnels and boreholes were discarded, thus leaving 132 free-field and urban free-field sites. Their distribution in the Swiss territory is illustrated in Fig. 2, whereas Tables 1 and 2 summarise the distribution according to the soil classification in the Swiss building codes SIA-261 (2014) and in the geology/tectonic units of the macroseismic amplification map, respectively. The soil classification is assigned based on S-wave measurements available for 91 station sites. As for the geological/tectonic units of the macroseismic amplification map, only 109 of the 132 considered seismic station sites have an assignment. The other 23 stations are mostly located on rock formations for which no IDP are available.

For each of the considered seismic stations, empirical amplification functions are routinely computed by using the SED system after each earthquake, using empirical spectral modelling (Edwards et al. 2013). The method is equivalent to the well-known approach in which source, path, and site effects are separated through a generalised inversion (Field and Jacob, 1995). In particular, for each recorded event, the source spectrum is computed with associated stress drop and moment magnitude, taking into account regional geometrical decay and path attenuation (Edwards and Fäh 2013). Finally, the elastic site amplification function is extracted for each processed earthquake, resulting in event-specific amplification added to the statistical representation of the database site response functions. With time, after many processed 


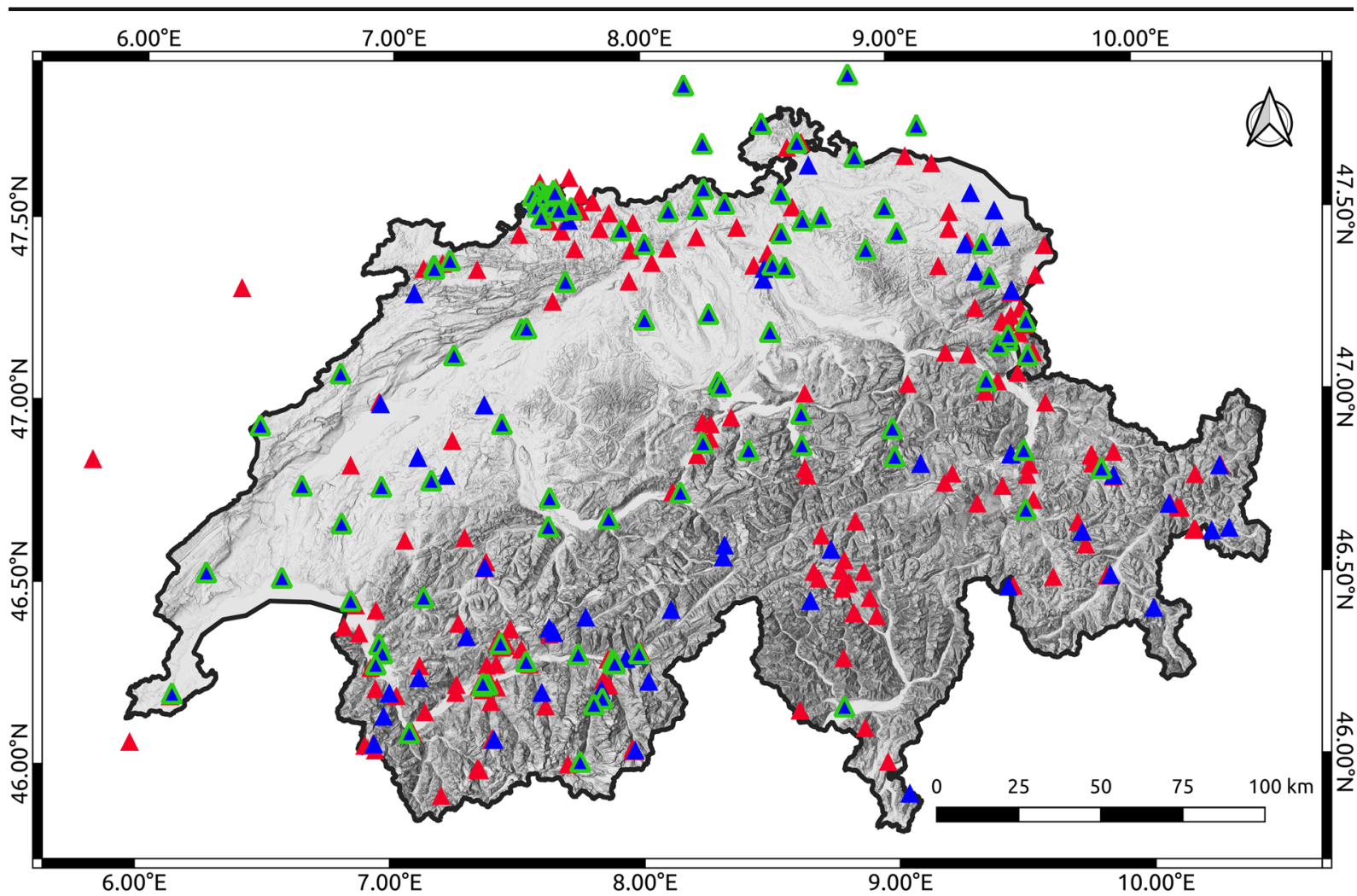

Fig. 2 Distribution of present and past permanent seismic stations in Switzerland (http://seismo.ethz.ch/en/home/). The blue triangles represent stations that have an assignment to a geologic/tectonic unit in Table 2. The triangles with a green border represent stations for which S-wave measurements were performed, and therefore, a soil class can be assigned. The red triangles are the remaining active and non-active seismic stations not used in this study. The map background is the large-scale topographic landscape model of Switzerland (Swisstopo 2020)

3.2 PSA amplification to macroseismic amplification factors

A macroseismic amplification factor $\Delta I m$ was assigned to each seismic station according to the station position in the macroseismic amplification map. At the same

the first $z$ metres of the Swiss reference rock condition, according to Poggi et al. (2011). $Q W L$, quarter-wavelength velocity at a given period as defined in Poggi et al. (2011)

\begin{tabular}{|c|c|c|c|c|c|c|c|c|}
\hline \multicolumn{9}{|c|}{ Seismic station classification } \\
\hline \multirow[t]{2}{*}{ SIA soil class } & A & B & C & D & & \multicolumn{2}{|l|}{$\mathrm{E}$} & N.C. \\
\hline & $V_{S, 30} \geq 800$ & $500 \leq V_{S, 30}<800$ & $300 \leq V_{S, 30}<500$ & \multicolumn{2}{|c|}{$V_{S, 30}<300$} & \multicolumn{2}{|c|}{$\begin{array}{l}\text { Classes C and D } \\
\text { with thickness } \\
\text { 5-20 m over rock }\end{array}$} & - \\
\hline $\mathrm{N}^{\mathrm{o}}$ of stations & 16 & 26 & 29 & \multicolumn{2}{|l|}{9} & \multicolumn{2}{|l|}{10} & 42 \\
\hline \multicolumn{9}{|c|}{ Swiss reference rock condition } \\
\hline$Z(\mathrm{~m})$ & 10 & 20 & 30 & 50 & 100 & $\begin{array}{l}\text { QWL } \\
\qquad(T=0.3 \mathrm{~s})\end{array}$ & $\begin{array}{l}\text { QWL } \\
\qquad(T=1.0 \mathrm{~s})\end{array}$ & $\begin{array}{l}\text { QWL } \\
\qquad(T=2.0 \mathrm{~s})\end{array}$ \\
\hline$V_{S, Z}(\mathrm{~m} / \mathrm{s})$ & 1036 & 1072 & 1105 & 1174 & 1331 & 1314 & 2024 & 2548 \\
\hline
\end{tabular}


Table 2 Summary of the number of seismic stations $\mathrm{N}^{\mathrm{o}}$ per geologic/tectonic unit. The classification is the same used in the macroseismic amplification map (ID in Fäh et al. (2011)). IDP (intensity data points) are the number of macroseismic observations used to estimate the values in the macroseismic intensity amplification map

\begin{tabular}{|c|c|c|c|}
\hline ID & Geologic unit & $\mathrm{N}^{\mathrm{o}}$ & IDP \\
\hline 1 & Older fluvioglacial gravel & 1 & 21 \\
\hline 2 & Alluvial midland molasse & 3 & 249 \\
\hline 3 & Alluvial plains & 22 & 419 \\
\hline 4 & Calcschists deposits (Bundnerschiefer) & 1 & 15 \\
\hline 5 & Alluvial Wildhorn nappe & 2 & 52 \\
\hline 6 & Aquitanian midland molasse & 2 & 132 \\
\hline 7 & Big Pleistocene landslides & 1 & 19 \\
\hline 8 & Upper marine molasse (Burdigalian) & 3 & 95 \\
\hline 9 & Debris cones & 7 & 369 \\
\hline 10 & Dogger Jura chain (Mesozoic) & 3 & 49 \\
\hline 11 & Fluvioglacial/glaciolacustrine gravels & 14 & 931 \\
\hline 12 & Flysch & 2 & 49 \\
\hline 13 & Gneiss micaschist & 4 & 69 \\
\hline 14 & Hillfoot debris & 3 & 51 \\
\hline 15 & Holocene landslides & 1 & 53 \\
\hline 16 & Keuper Jura chain (Mesozoic) & 2 & 15 \\
\hline 17 & Loess & 3 & 58 \\
\hline 18 & Malm cover & 3 & 39 \\
\hline 19 & Malm Jura chain (Mesozoic) & 3 & 83 \\
\hline 20 & Other alpine nappes & 1 & 78 \\
\hline 21 & Other facies of midland molasse & 2 & 65 \\
\hline 22 & Moraines on midland molasse & 10 & 846 \\
\hline 23 & Moraines on nappes & 2 & 137 \\
\hline 24 & Moraines on subalpine molasse & 1 & 28 \\
\hline 25 & Muschelkalk Jura chain (Mesozoic) & 4 & 49 \\
\hline 26 & Organic soils & 2 & 62 \\
\hline 27 & Tertiary graben & 2 & 26 \\
\hline 28 & Upper freshwater molasse & 5 & 257 \\
\hline 29 & Alluvial cover & 0 & 0 \\
\hline 30 & Big alluvial plains (subfacies) & 0 & 0 \\
\hline 31 & Lower freshwater molasse (Jura chain) & 0 & 63 \\
\hline 32 & Lower freshwater molasse (Prealps) & 0 & 52 \\
\hline 33 & Glacier & 0 & 0 \\
\hline 34 & Internal Jura & 0 & 0 \\
\hline 35 & Thick Quaternary deposit & 0 & 10 \\
\hline 36 & Moraines on flysch & 0 & 33 \\
\hline 37 & Sediment cover (Perm/Verrucano) & 0 & 18 \\
\hline 38 & Lower marine molasse & 0 & 0 \\
\hline 39 & Lower Cretaceous internal Jura & 0 & 33 \\
\hline 40 & Unknown & 22 & 0 \\
\hline
\end{tabular}

time, a set of macroseismic amplification factors $A f$ was derived from the measured PSA amplification factors $(A m p(T))$, using the ground motion to intensity conversion equations (GMICE), proposed by Faenza and Michelini (2010 and 2011), FM10\&11:

$$
\begin{aligned}
I_{M C S}= & (1.24 \pm 0.33)+(2.47 \pm 0.18) \log (S A) \sigma \\
= & 0.53 \text { for } T=0.3 s \\
I_{M C S}= & (3.12 \pm 0.16) \\
& +(2.05 \pm 0.11) \log (S A 1.0 s) \sigma \\
= & 0.36 \text { for } T=1.0 s \\
& +(2.00 \pm 0.10) \log (S A 2.0 s) \sigma \\
I_{M C S}= & (4.31 \pm 0.10) \\
= & 0.29 \text { for } T=2.0 s \\
& +(2.58 \pm 0.14) \log (P G A) \sigma \\
= & 0.35 \text { for } P G A \\
I_{M C S}= & (5.11 \pm 0.07) \\
& +(2.35 \pm 0.09) \log (P G V) \sigma \\
= & 0.26 \text { for } P G V \\
I_{M C S} & \\
& \\
& \\
& \\
& \\
& \\
& \\
&
\end{aligned}
$$

where $I_{M C S}$ is the macroseismic intensity in MercalliCancani-Sieberg, PGV is the peak ground velocity, PGA is the peak ground acceleration, and SA is the spectral acceleration at $0.3,1.0$, and $2.0 \mathrm{~s}$ period $T$. The FM10\&11 relationships are suitable for Switzerland and are implemented in SED-ShakeMap (Cauzzi et al. 2015). Moreover, the FM10\&11 relationships have the advantage that they were developed using orthogonal regression, making possible their use in two directions, from ground motion parameters to intensity and from intensity to ground motion parameters. Each equation allows deriving an intensity increment $A f$ : 


$$
\begin{aligned}
A f & =I_{M C S}-I_{M C S r e f}=b \log \left[\frac{P G X(T)}{P G X_{\text {ref }}(T)}\right] \\
& =b \log [\operatorname{Amp}(T)]
\end{aligned}
$$

where $b$ is the slope coefficient of the relationships [1] to [5]. Although the amplification map of Switzerland is based on EMS-98, it shares almost similar intensity values with the MCS up to about intensity VIII (e.g. Musson et al. 2010; Cauzzi et al. 2015; Panzera et al. 2018). Therefore, sets of $A f$ values were derived from PSA amplification functions at the periods of $0.3 \mathrm{~s}$, $1.0 \mathrm{~s}$, and $2.0 \mathrm{~s}$, as well as for PGV and PGA.

\section{Comparison between $\Delta I m$ and $A f$ factors}

In Fig. 3, the $A f$ values are plotted against $\Delta I m$, highlighting very low coefficients of correlation $R$ squared $\left(R^{2}\right)$ due to the structure of macroseismic intensity that is conserved in the $\Delta I m$ (Pettenati and Sirovich 2007). The coefficient of correlation is estimated as the ratio between the sum of squares due to regression (RSS) and total sum of squares (TSS). Moreover, the high $\Delta I m$ variability is expected, if we consider that the macroseismic map does not capture small-scale variations in seismic site response, because it is built considering average $\Delta I m$ in an area.

The linear fits in Fig. 3 were computed for two different datasets which differ only for the $\Delta I m$ assigned to the alluvial plains (grey points with blue dots and grey points with red dots). Fäh et al. (2011) obtained for this geologic/tectonic unit a median macroseismic amplification factor 0.33 , but they suggested to use conservatively the 75 th percentile value 1.05 in the shake map application (Cauzzi et al. 2015). In this way, the authors wanted to account for the urban development in the twentieth century into areas of unfavourable soil behaviour in alluvial plains. These areas are not sufficiently covered by historical IDP used to derive the amplification map.

Since the soil S-wave velocity reference for $\Delta \mathrm{Im}$ is lower than the rock reference for $A f$, the curves in Fig. 3 are above the 1:1 green lines. Moreover, for PGA, PGV, and $\mathrm{SA}$ at $0.3 \mathrm{~s}$, the curves are almost parallel to the 1:1 green lines, which is desirable. For the SA periods 1.0 and $2.0 \mathrm{~s}$, the curves are not parallel to the 1:1 curve, with a decreasing trend towards higher $\Delta I m$. With increasing $\Delta I m$, observed amplification $A f$, derived from ground motion at longer periods, becomes smaller with respect to $T=0.3 \mathrm{~s}$. For longer periods, the influence of the deeper structure is more relevant. Therefore, it seems that the deeper structure is not reflected in the amplification derived from IDP. When the conservative 75th percentile of the observed $\Delta I m$ for alluvial plains is used, for the periods 1.0 and $2.0 \mathrm{~s}$, the linear fit line falls below the 1:1 green line, which is unphysical (Fig. 3). In this case, at $\Delta I m=0.0$, the $A f$, obtained as $d \Delta f=A f-\Delta I m$, is in the range $0.18-0.46$ (Fig. 3), and it is higher if only PGA, PGV, and $T=0.3 \mathrm{~s}$ are considered $(0.28 \leq d \Delta f \leq$ $0.46)$. The linear fits performed using median values of the observed $\Delta I m$ show slope coefficients higher than 0.82 for PGA, PGV, and $T=0.3 \mathrm{~s}$, and it is possible to observe that the linear fit lines lie always above the 1:1 green lines. At $\Delta I m=0.0$, the $A f$, obtained as $d \Delta f=A f$ $-\Delta I m$, is in the range $0.27-0.56$ (Fig. 3). For PGA, $\mathrm{PGV}$, and $T=0.3 \mathrm{~s}$, the range is narrower $(0.32 \leq d \Delta f \leq$ $0.56)$. The latter is the closest $d \Delta f=A f-\Delta I m$ to the suggested constant correction term of 0.47 ( $1 / 2$ intensity units) of Fäh et al. (2011), which was suggested to account for the necessary adjustment to Swiss reference rock conditions.

The $d \Delta f$ computed for each considered seismic station site can also be analysed to assess if their distribution is normal and to determine its mean value (Fig. 4). Using the Kolmogorov-Smirnov test (Murphy et al. 1968), we found, with a $95 \%$ confidence level, that the data are significantly drawn from a normal distribution ( $p$ value $\geq 0.05$ ), although distributions are moderately skewed (skewness $\leq 0.5$ ). The analysis was performed using the median $\Delta I m$ for alluvial plains. The $d \Delta f$ are distributed following a normal distribution, with the mean $d \Delta f$ values between 0.17 and 0.52 . These values are in agreement with the one observed in Fig. 3.

From the performed analysis, we obtain that the macroseismic amplification map and consequently $\Delta I m$ values are better represented when $A f$ is computed at $T=0.3 \mathrm{~s}, \mathrm{PGV}$, and PGA. Most of the observed $\Delta I m$ were derived from intensities in the lower intensity grades below VI. At these intensities, no damage occurs, and intensity is best correlated with PGV and PGA (e.g. Omine et al. 2008). Therefore, observed $A f$ derived from PGV and PGA might best compare to $\triangle I m$. The correction factor (mean $d \Delta f$ ) due to the different soil/rock references is therefore best measured from PGV $(0.37 \leq$ $d \Delta f \leq 0.42)$ and PGA $(0.52 \leq d \Delta f \leq 0.56)$. This range of values is the closest to the constant correction of 0.47 (1/2 intensity units) suggested by Fäh et al. (2011). 

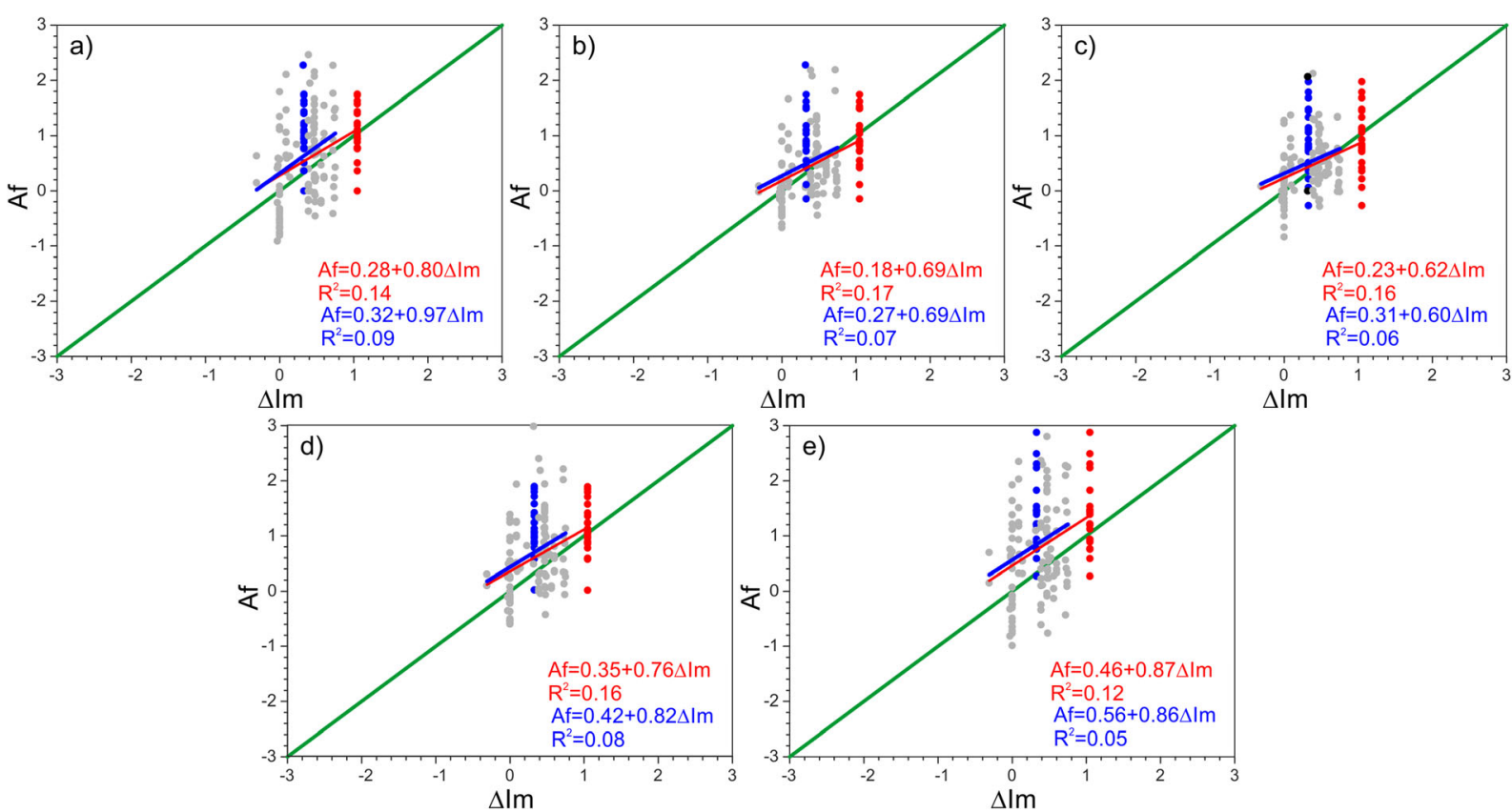

Fig. 3 Scatterplot showing the $\Delta I m$ vs. $A f$ (grey dots), computed at different periods. a $0.3 \mathrm{~s}, \mathbf{b} 1.0 \mathrm{~s}, \mathbf{c} 2.0 \mathrm{~s}, \mathbf{d}$ PGV, and e PGA. The median $\Delta I m$ vs. $A f$ values for alluvial plain are plotted as blue dots, whereas in red the conservative 75 th percentile. Continuous

When we consider intensity grades, where damage to buildings is described (VI and above), we should not use PGA anymore, but PGV and SA at the period of the

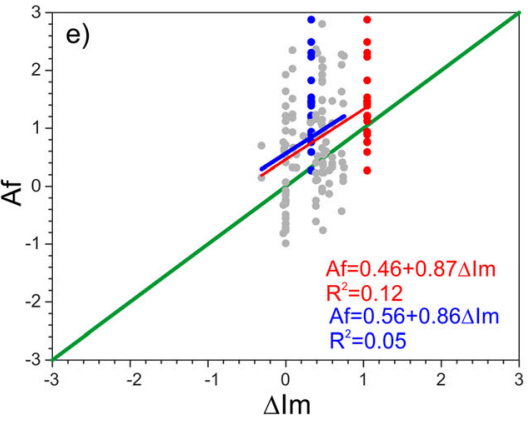

lines are the best fit curves obtained considering grey and blue dots (blue line) or grey and red dots (red line), respectively. Green lines are the $1: 1$ lines

buildings (e.g. Wu, 2003). For the Swiss building stock, Michel et al. (2017) suggested SA at $0.3 \mathrm{~s}$ when considering the vibration periods of typical buildings.
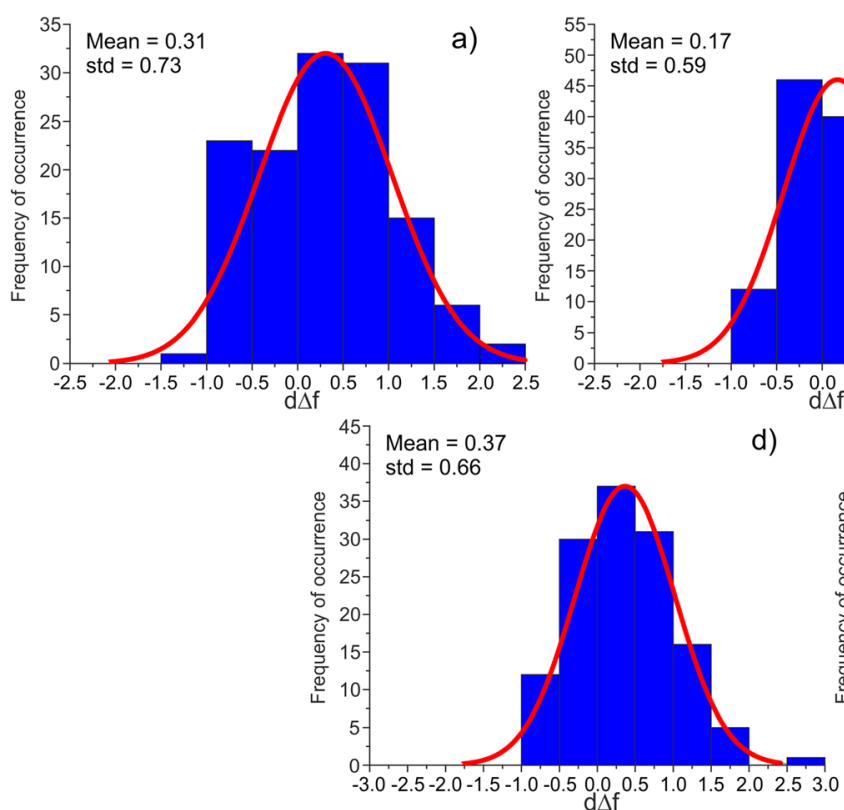

b)

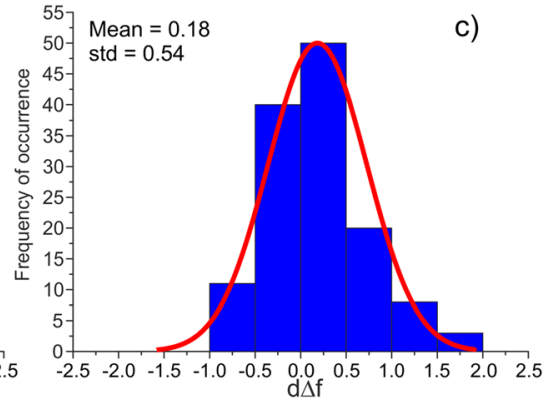

e)

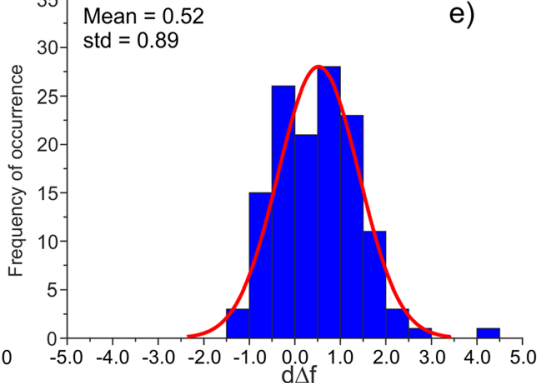

Fig. 4 The $\mathrm{d} \Delta \mathrm{f}$ distributions using the mean of the observed $\Delta \mathrm{Im}$ in big alluvial plains, for the considered ground motion parameters at different periods. a $0.3 \mathrm{~s}, \mathbf{b} 1.0 \mathrm{~s}, \mathbf{c} 2.0 \mathrm{~s}, \mathbf{d}$ PGV, and e PGA. The red lines represent the fitted normal distribution 
Therefore, for the higher intensity grades, the best selection to correct for the difference in reference soil/rock condition is from $T=0.3 \mathrm{~s}(0.31 \leq d \Delta f \leq 0.32$, see Figs. 3 and 4$)$, together with PGV $(0.37 \leq d \Delta f \leq 0.42$, see Figs. 3 and 4).

\section{Reference soil condition from the available $V_{S, 30}$ of the geologic/tectonic units}

In section 3, we have shown that there exists a discrepancy of $d \Delta f$ between $A f$ and $\Delta I m$, which can be explained in terms of different reference soil/rock conditions. In particular, the Swiss reference rock used in the computation of the empirical amplification functions is stiffer than the one expected for the macroseismic amplification map. This aspect can be highlighted using the IDP and corresponding $V_{S, 30}$ values for each geologic unit (Table 2).

Figure 5 shows that only 8 classes, with a low number of intensity observations $(<100)$, have no $V_{S, 30}$ measurements. About $40 \%$ of the IDP belong to 'fluvioglacial/glaciolacustrine gravels' and 'moraines on midland molasses' formations. The weighted average of $V_{S, 30}\left(\bar{V}_{S, 30}\right)$ and the corresponding standard deviation $\left(\sigma_{V S, 30}\right)$ were computed using the following relationships:

$\bar{V}_{S, 30}=\frac{\sum V_{S, 30_{i}}{ }^{* \mathrm{IDP}_{i}}}{\sum \mathrm{IDP}_{i}}$

$\sigma_{V S, 30}=\sqrt{\frac{\sum\left(V_{S, 30_{i}}-V_{S, 30}\right) * \mathrm{IDP}_{i}}{\frac{M-1}{M} \sum \mathrm{IDP}_{i}}}$

where $M$ is the number of weight that are not equal to zero in each soil class.

From this analysis, it is possible to affirm that most of the IDP have a $V_{S, 30}$ in the range $258-687 \mathrm{~m} / \mathrm{s}$ with an average value of $472 \pm 214 \mathrm{~m} / \mathrm{s}$. Moreover, it is also possible to highlight that the highest and lowest $V_{S, 30}$ values are related to few IDP on the 'malm cover' and 'organic soil formations'.

In order to highlight the soil classes for which the macroseismic amplification map might underestimate or overestimate the amplification level, the $d \Delta f$ were plotted versus the SIA-261 (2014) soil classification (Fig. 6 and Table in supplementary material S1 in which the obtained $d \Delta f$ values for each SIA-261 (2014) soil class are summarised). From Fig. 6, it is possible to infer that, as expected, $d \Delta f$ is negative for soil class $\mathrm{A}$ and it is positive for the remaining soil classes. For soil type A, there are many instrumented sites on hard rock conditions with high $\mathrm{S}$-wave velocities (soil class $\mathrm{A}$ is defined as $V_{S, 30} \geq 800 \mathrm{~m} / \mathrm{s}$ ), while IDP in localities on hard rock are expected to be rare, because urbanised areas generally are not on hard rock but on sediments or weathered sedimentary rock. Therefore, the macroseismic amplification map does not cover well sites on hard rock. This trend is well observed in all the considered spectral ordinates, but particularly for $T=0.3 \mathrm{~s}, \mathrm{PGV}$, and PGA (Fig. 6). Moreover, it is possible to presume that the first soil class (starting with hard material soil class A), in which a positive $\Delta I m$ is expected for the macroseismic amplification map, is in the velocity range of soil class $\mathrm{B}\left(500 \leq V_{S, 30}<800 \mathrm{~m} / \mathrm{s}\right)$. In particular, this analysis reveals that the average $d \Delta f$ for soil classes $\mathrm{B}$ and $\mathrm{C}$ are the closest to the values in Fig. 3, confirming that these two classes are the most represented in the dataset used to draw the macroseismic amplification map. The $d \Delta f$ for these classes can be explained mainly as difference between the reference soil condition for the intensity prediction equation and the Swiss reference rock. For soil class $\mathrm{A}, d \Delta f$ is lower than 0.20 (average value of all the considered SA for soil class B), meaning that the macroseismic amplification map is slightly overestimating amplification. On the other hand, for soil class $\mathrm{D}, d \Delta f$ is always much higher with respect to the other soil classes and mainly above $d \Delta f>0.40$ (average value of all the considered SA for soil class $\mathrm{C}$ ). The overestimation on soil class $\mathrm{A}$ and underestimation on soil class D are due to the fact that the macroseismic amplification map was derived considering observations mainly from soil classes B and C (more favourable to human settlement). This means that the macroseismic amplification map underestimates the amplification on sites with soil class D, as already suggested by Fäh et al. (2011).

The analysis was also performed plotting the $V_{S, 30}$ versus $d \Delta f$ (Fig. 7), obtaining similar results as in Fig. 6 . In particular, for SA $(0.3 \mathrm{~s}), \mathrm{PGV}$, and PGA, $d \Delta f$ with $V_{S, 30}$ between about 400 and $600 \mathrm{~m} / \mathrm{s}$ are the closest to the values in Fig. $3 ; d \Delta f$ for $V_{S, 30}$ lower than $300 \mathrm{~m} / \mathrm{s}$ are always the highest; and the $d \Delta f$ with $V_{S, 30}$ higher than $625 \mathrm{~m} / \mathrm{s}$ tend to be negative. This means that the macroseismic amplification map has the tendency to provide too high values for non-weathered rock 


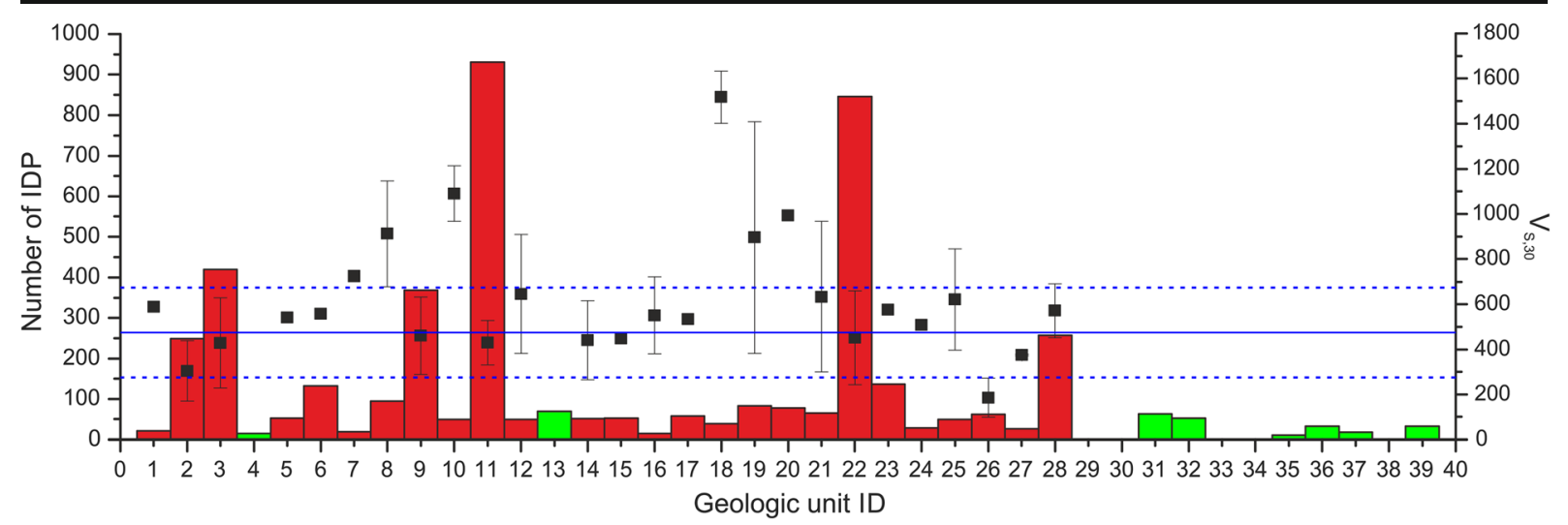

Fig. 5 Histograms showing the number of IDP for each geologic unit. Red bars are related to units for which at least one $V_{S, 30}$ measurement is available, whereas green bars are units for which no $V_{S, 30}$ estimates exist. Black squares and bars are the average

materials and too low values for the soft sediments in soil class D. Moreover, from Fig. 7, we can provide an estimate of the reference soil condition of the macroseismic amplification map, in terms of a $V_{S, 30}$ range of $400-600 \mathrm{~m} / \mathrm{s}$.
$V_{S, 30}$ and standard deviations for each geologic unit. Continuous and dashed blue lines are $V_{S, 30}$ weighted average and standard deviation for the entire dataset

\section{Relationships between $A f$ and $V_{S}$ proxy}

The relationships between macroseismic intensity increment $A f$ and simplified site response proxies; the quarter-wavelength velocity $\left(V_{\mathrm{QWL}}\right)$ at $0.3 \mathrm{~s}, 0.5 \mathrm{~s}$, and
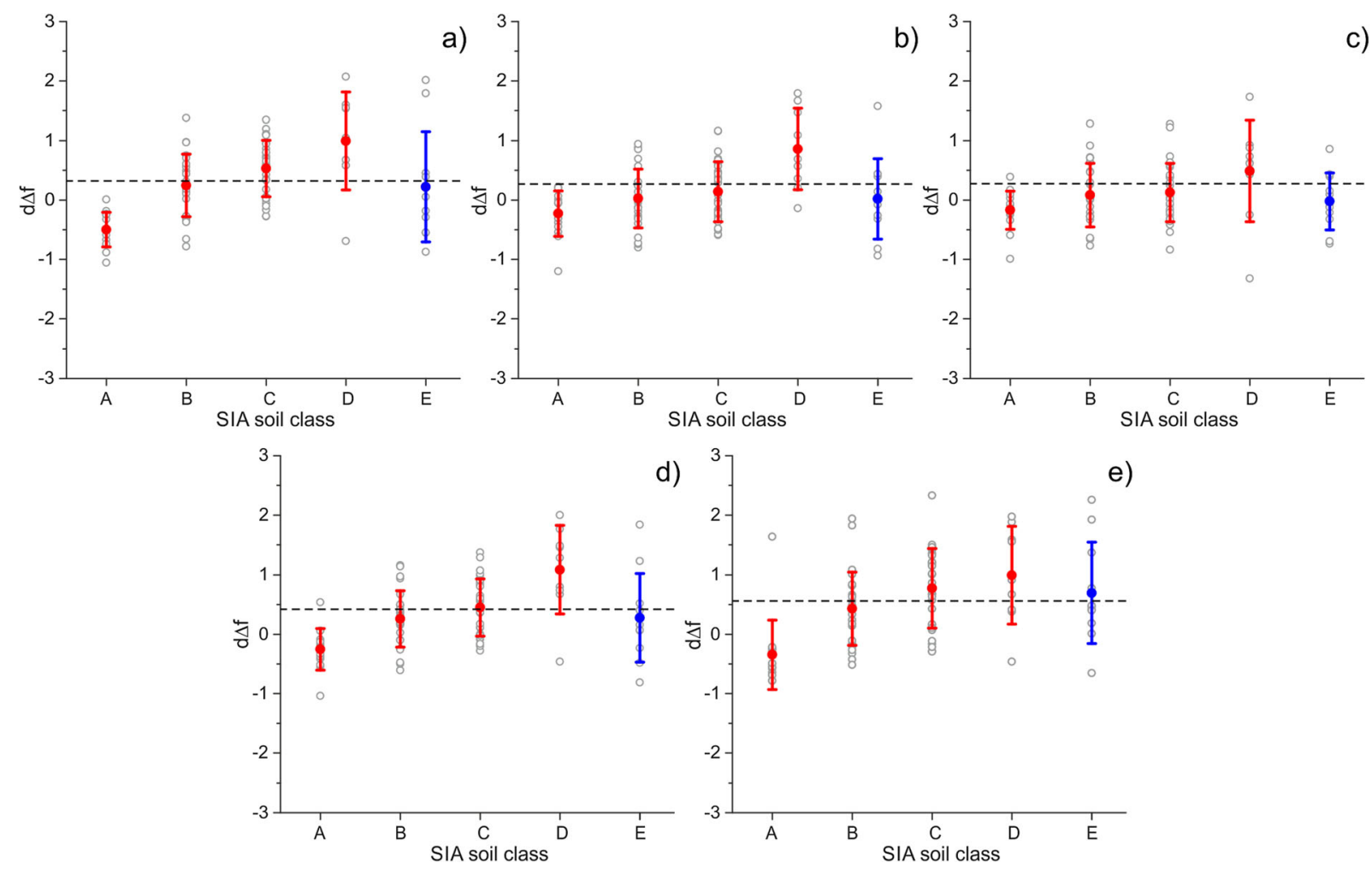

Fig. 6 SIA-261 (2014) soil classes assigned to each seismic station vs. $d \Delta f$ computed at different periods (grey dots). a $0.3 \mathrm{~s}$, b $1.0 \mathrm{~s}, \mathbf{c} 2.0 \mathrm{~s}, \mathbf{d}$ PGV, and e PGA. Red dots and bars are the $d \Delta f$ average and standard deviations values for each soil class,

respectively. The soil class $\mathrm{E}$ (blue dot and bars) was considered alone. Dashed lines indicate $d \Delta f=A f-\Delta I m$ for each considered $\mathrm{SA}$, as obtained from the regression in Fig. 3 by using the median $\Delta I m$ for alluvial plains (blue line) 


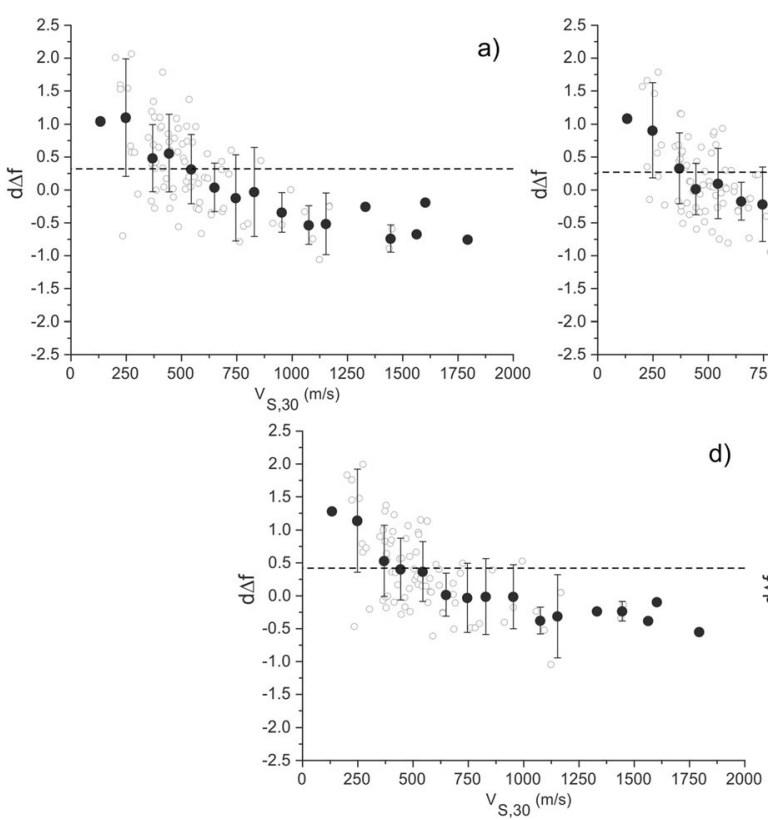

Fig. $7 V_{S, 30}$ assigned to each seismic station vs. $d \Delta f$ computed at different periods. a $0.3 \mathrm{~s}, \mathbf{b} 1.0 \mathrm{~s}, \mathbf{c} 2.0 \mathrm{~s}, \mathbf{d}$ PGV, and e PGA. Grey dots are the $d \Delta f$ at each station, whereas black dots and bars are the

$1.0 \mathrm{~s}$; and the average velocity $\left(V_{S, Z}\right)$, with $Z$ equal to 10 , $20,30,50$, and $100 \mathrm{~m}$, were derived at each seismic station from measured velocity profiles. In Figs. 8 and 9, we show the scatterplot $V_{S, Z}$ versus $A f$ for spectral period $0.3 \mathrm{~s}$ and PGV, but in supplementary material S0, the scatterplots for spectral periods $1.0 \mathrm{~s}$ and $2.0 \mathrm{~s}$ as well as for PGA are also available. The $V_{S, Z}$, when plotted versus $A f$, highlight a non-linear distribution of points. Therefore, several non-linear curves were tested for the fit, assuming as best a logarithmic function having the following form:

$\Delta I s=a+b \log _{10}\left(V_{X}\right)$

where $V_{X}$ is either $V_{S, Z}$ or $V_{\mathrm{QWL}}$. Such functional form is suggested in empirical ground motion prediction equations (e.g. Cauzzi et al. 2015) to account for the site amplification. From our analysis, we excluded too low and too high $A f$ estimating the mean and standard deviation values for each considered SA period. This selection was made in order to remove seismic stations located in peculiar geologic settings. The $V_{X}$ values were then subdivided in bins of $100 \mathrm{~m} / \mathrm{s}$, with associated mean and standard deviation. In a similar fashion, $A f$ falling in each velocity bin were averaged and the standard deviation was computed (blue squares and bars in Figs. 8 and 9 and in Fig. S0). The best fit was found

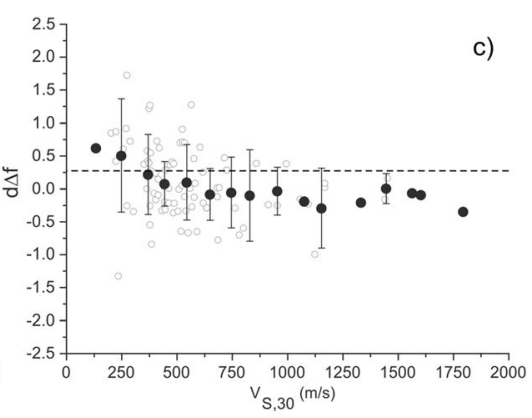

e)

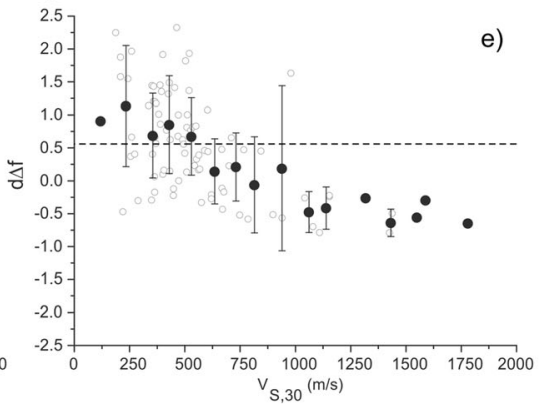

average and standard deviations $d \Delta f$ values for bins of $V_{S, 30}$. Dashed lines indicate $d \Delta f$ for each considered SA, as obtained in Fig. 3 by using the median $\Delta I m$ for alluvial plains

assuming both $V_{X}$ and $A f$ as affected by errors, using then $\sigma_{V_{X}}$ and $\sigma_{A f}$ standard deviations as weights. In this way, points with high standard deviations were weighted less in the fitting. Moreover, the non-linear fit was made forcing the curve through the coordinates $V_{X}$ equal to Swiss rock reference condition and $A f=0$, for all the considered SA (green diamond in Figs. 8 and 9 and in Fig. S0).

The obtained regression equations, with the corresponding coefficient of determination $\left(R^{2}\right)$, are plotted in Figs. 8 and 9 (S0 for PGA and the other spectral periods). For all the considered SA periods, the $R^{2}$ is high enough to affirm that a good correlation exists between the considered parameters. Anyway, in general, the best correlation with the considered proxies is obtained with $A f$ estimated at $0.3 \mathrm{~s}$ and from PGV (Table 3). For the spectral periods $1.0 \mathrm{~s}$ and $2.0 \mathrm{~s}$, the decrease in $R^{2}$ could be explained considering that velocity proxies alone are not sufficient to explain low frequency site effects (e.g. valleys). For PGA, the correlation decreases with increasing thickness of the considered structure.

The $d \Delta f$ obtained in the analysis of Fig. 3 can be used to infer an indication on the macroseismic amplification map $V_{X}$ soil reference condition. Therefore, the $d \Delta f$ of the considered SA, PGV, and PGA were used to find the 

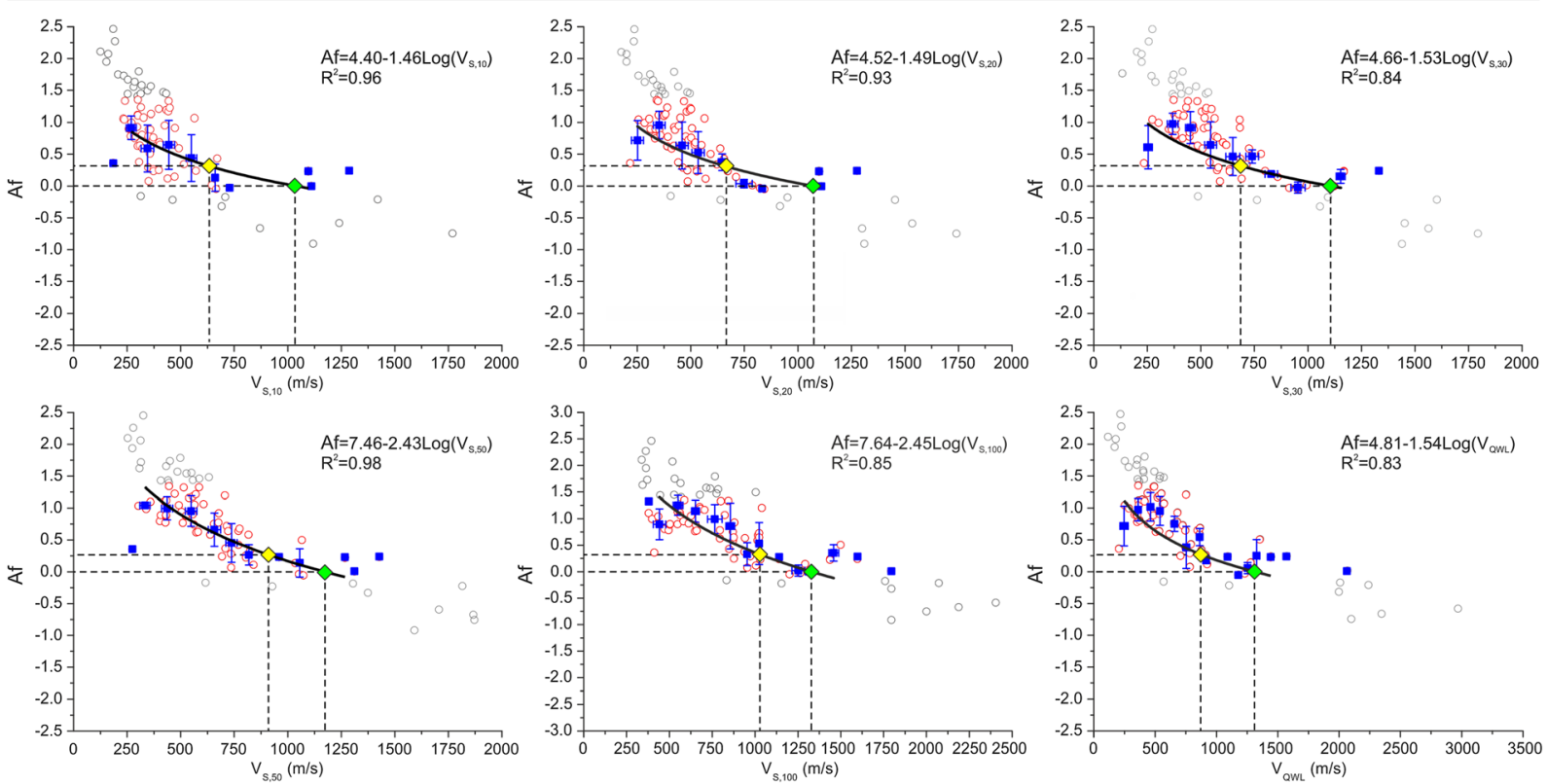

Fig. 8 Scatterplots showing the $V_{S, Z}$ and $V_{\mathrm{QWL}}$ vs. $A f$ at spectral period $0.3 \mathrm{~s}$ (grey dots). Red dots represent the selected points falling inside the standard deviation and then used for the analysis. Blue squares and bars are the mean and standard deviation for each bin of velocity. Black lines are best fit curves forcing the fitting through the coordinates $V_{S, Z}$ equal to the Swiss reference rock condition and $A f=0$. Green and yellow diamonds indicate Swiss reference rock and expected macroseismic map reference conditions, respectively corresponding $V_{X}$ (yellow diamonds in Figs. 8 and 9 and in Fig. S0) of the reference soil condition in the 'macroseismic amplification' map. Table 4 summarises the $V_{X}$ value at which $\Delta I m=0$ is expected. The estimated values are only indicative, as especially $d \Delta f$ are affected by high variability (see Fig. 3). The mean values for the different $V_{X}$ in Table 4 can be considered a representation of the reference velocity profile of the 'macroseismic amplification' map.

\section{Statistical significance of geological/tectonic classification with respect to the $\boldsymbol{A} f$}

We also tested the significance of the geological/ tectonic classification of the macroseismic amplification map when this is related to the measured site response at seismic stations. We verified if the local amplifications observed at stations from the same geological/tectonic unit are homogeneous and if each unit actually differs from the amplification behaviour observed at the other formations.

For this purpose, we first classified the amplification factors for PSA (Amp) at period $T$ of $0.3,1.0$, and $2.0 \mathrm{~s}$; PGV; and PGA measured at every Swiss station, according to the geological/tectonic affiliation of the latter. The number of stations belonging to each unit is generally quite low (Table 2 ; in average 3.22 stations per class), with 11 classes lacking any stations. We assumed to be able to make some inference on the statistical significance of the amplification behaviour of the units hosting at least 4 stations. Only 7 units fulfil this criterion: 'moraines on midland molasses', 'alluvial plains, debris cones', 'fluvioglacial/glaciolacustrine gravels', 'Gneiss micaschist', 'Muschelkalk Jura chain (Mesozoic)', and 'upper freshwater molasses'.

Figure 10, first five panels, displays the distribution of the considered Amp by geologic/tectonic class; factors from individual sites appear to approximately follow a consistent behaviour within each class, with moderate scatter (in $77 \%$ of the cases, the standard deviation of $\log (A m p)$ for an individual class is smaller than the $\sigma$ of the overall population). Some classes (e.g. 'upper freshwater molasses') bear greater homogeneity (smaller $\sigma$ ) than others (e.g. 'moraines on midland molasses'), generally in a consistent way for all periods.

The standard deviations for each class of the PSA amplification factors were also translated into $\sigma$ of macroseismic intensity increment $\left(\sigma\left(A_{f}\right)\right.$ in Fig. 10 lower right subplot), applying Eqs. 1-5; hence, they can be 


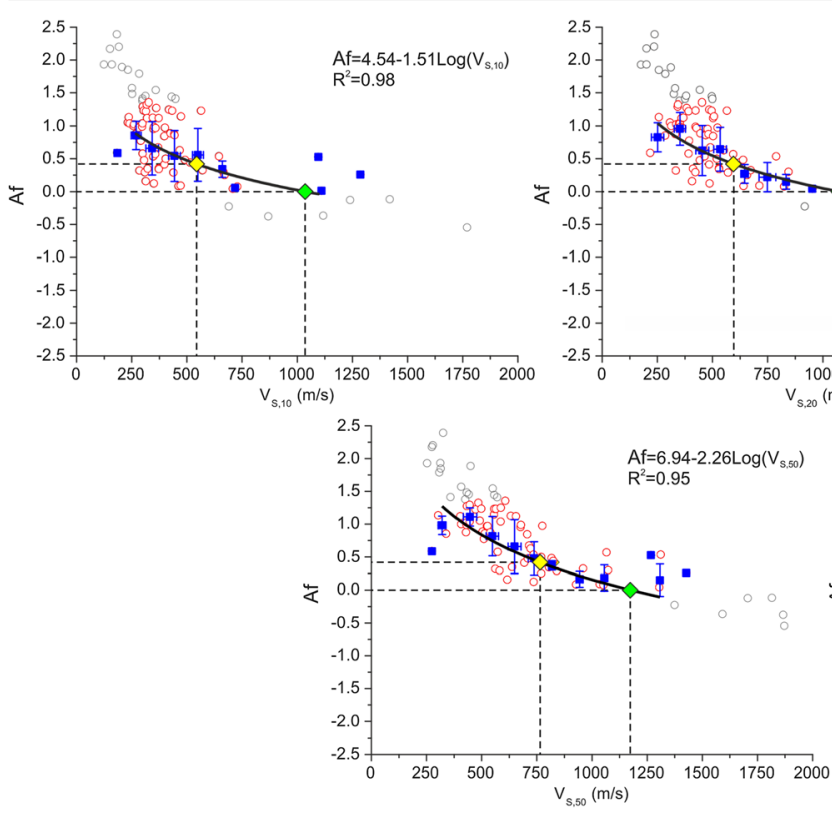

Fig. 9 Scatterplots showing the $V_{S Z Z}$ and $V_{\mathrm{QWL}}$ vs. $A f$ from PGV (grey dots). Red dots represent the selected points falling inside the standard deviation and then used for the analysis. Blue squares and bars are the mean and standard deviation for each bin of velocity.

collated with the corresponding $\sigma$ from the IDP database (Fäh et al. 2011). The numerical values are reported in Table 5. Standard deviations derived from empirical amplifications at Swiss stations are generally lower (by $\sim 25 \%$ ) than the $\sigma\left(A_{f}\right)$ directly obtained from the IDP. Interestingly, geological classes with wider variability in macroseismic data (black dashed line in Fig. 10) preserve higher values of standard deviations also when the latter are indirectly extracted from recorded earthquake data (coloured lines). This suggests that some classes are intrinsically characterised by a higher (or a lower) variance of the site response, independently of the method used to estimate it.

Table 3 Summary of the regression coefficients $\left(R^{2}\right)$, obtained from the fitting $V_{S, Z}$ vs. $A f$ and $V_{\mathrm{QWL}}$ vs. $A f$

Fitting forced through the Swiss reference rock condition and $A f=0$

\begin{tabular}{lcccccc}
\hline SA & $V_{S, 10}$ & $V_{S, 20}$ & $V_{S, 30}$ & $V_{S, 50}$ & $V_{S, 100}$ & $V_{\mathrm{QWL}}$ \\
\hline $0.3 \mathrm{~s}$ & 0.96 & 0.93 & 0.84 & 0.98 & 0.85 & 0.83 \\
$1.0 \mathrm{~s}$ & 0.92 & 0.97 & 0.81 & 0.97 & 0.80 & 0.81 \\
$2.0 \mathrm{~s}$ & 0.91 & 0.92 & 0.86 & 0.88 & 0.87 & 0.87 \\
PGV & 0.98 & 0.96 & 0.92 & 0.95 & 0.83 & - \\
PGA & 0.91 & 0.94 & 0.76 & 0.88 & 0.80 & - \\
\hline
\end{tabular}
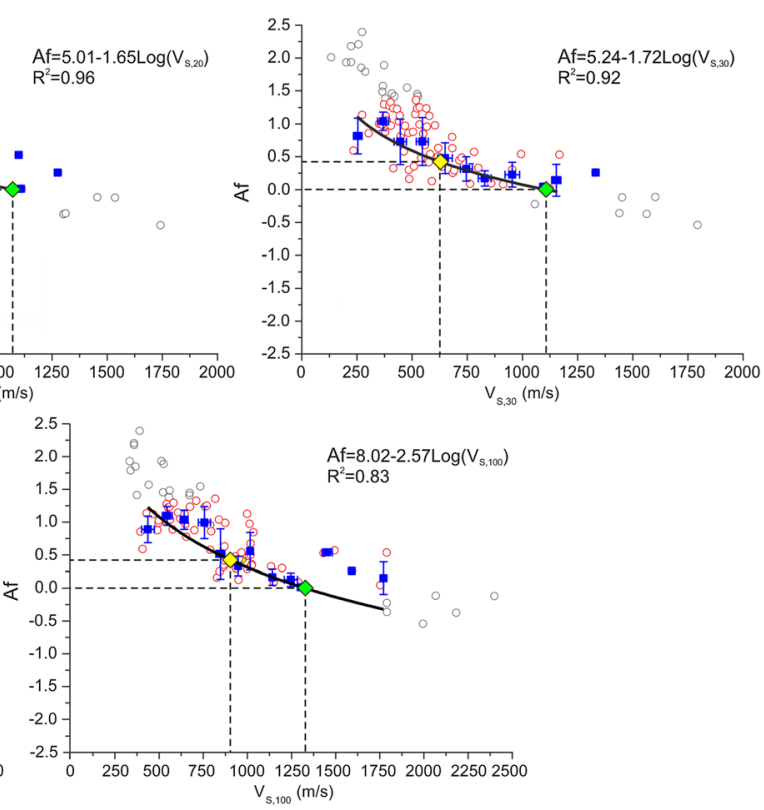

Black lines are best fit curves forcing the fitting through the coordinates $V_{S, Z}$ equal to the Swiss reference rock condition and $A f=0$. Green and yellow diamonds indicate Swiss reference rock and expected macroseismic map reference conditions, respectively

To determine the amplification ordinate (PGA, $T=$ $0.3-2.0 \mathrm{~s}, \mathrm{PGV}$ ) for which the geological/tectonic subdivision of the 'macroseismic amplification' map is more successful in defining homogeneous classes, we compute for each ordinate a pseudo-coefficient of determination:

$$
\begin{aligned}
\operatorname{pseudo} R^{2} & =1-\frac{\mathrm{SSD}}{\mathrm{TSS}} \\
& =1-\frac{\sum_{c=1}^{p}\left(\sum_{j=1}^{m}\left(a_{j}-\overline{a_{c}}\right)^{2}\right)}{\sum_{i=1}^{n}\left(a_{i}-\bar{a}\right)^{2}}
\end{aligned}
$$

where TSS is the total sum of the squares over the entire population of $n$ amplification factors in log scale $a_{i}$ $(\log (A m p))$, and SSD is the sum of the squared differences between each $a_{j}$ and the average $\overline{a_{c}}$ from its class. A high pseudo $R^{2}$ (its maximum value being 1 ) means that the considered classification groups the amplification factors into internally consistent subgroups; vice versa, values close to 0 denote an ineffective categorisation. According to the pseudo $R^{2}$ we obtained, the 'macroseismic amplification' map classification is the most effective for PGV (pseudo $R^{2}=0.42$ ), followed by the $0.3 \mathrm{~s}$ spectral period (0.39), PGA and $1 \mathrm{~s}$ spectral period (0.35), and finally $2 \mathrm{~s}$ spectral period $(0.28)$. This 
Table 4 Derived soil reference condition for the macroseismic amplification map using the $d \Delta f$ values obtained in Fig. 3 and the relationships for $V_{S, Z}$ found in Supplementary material and Figs. 8 and 9

\begin{tabular}{|c|c|c|c|c|c|c|c|}
\hline$V_{S, Z}(\mathrm{~m} / \mathrm{s})$ & $T=0.3 \mathrm{~s} \mathrm{~d} \Delta \mathrm{f}=0.32$ & $T=1.0 \mathrm{~s} \mathrm{~d} \Delta \mathrm{f}=0.27$ & $T=2.0 \mathrm{~s} \mathrm{~d} \Delta \mathrm{f}=0.31$ & $\mathrm{PGV} \mathrm{d} \Delta \mathrm{f}=0.42$ & PGA d $\Delta \mathrm{f}=0.56$ & Mean & std \\
\hline$V_{S, 10}$ & 623.05 & 575.44 & 483.29 & 535.15 & 516.14 & 544.50 & 48.46 \\
\hline$V_{S, 20}$ & 658.86 & 635.74 & 537.03 & 605.09 & 568.72 & 599.46 & 44.06 \\
\hline$V_{S, 30}$ & 686.44 & 725.98 & 559.21 & 634.35 & 611.45 & 640.85 & 58.07 \\
\hline$V_{S, 50}$ & 867.50 & 806.92 & 635.94 & 767.28 & 717.89 & 754.93 & 78.70 \\
\hline$V_{S, 100}$ & 972.20 & 988.20 & 874.09 & 906.15 & 833.96 & 913.06 & 58.22 \\
\hline$V_{\mathrm{QWL}}$ & 823.35 & 1416.32 & 1783.65 & - & - & - & - \\
\hline
\end{tabular}

behaviour was already highlighted by several authors (e.g. Wu 2003; Kaka and Atkinson 2004) who found that earthquake damage statistics show a closer correlation with the PGV distribution; in fact, $\mathrm{PGV}$ is a more reliable indicator of seismically induced strains in the shallow subsurface, thus more in accordance with damage distribution.

Finally, to determine whether the empirically observed amplification for a given class differs significantly from the behaviour of the other units, we collated the average $\log (A m p)$ values from every couple of considered classes through the unequal variances $t$ test (Welch
1947; see Bergamo et al. 2019 for similar applications). When the test's null hypothesis - which the two populations' means are statistically equivalent (with a 90\% confidence level) - is verified, the two geological/ tectonic units then have similar amplification behaviours; if the hypothesis is rejected, we infer that the two classes may have significantly different average responses. The matrices in Fig. 11 represent the outcomes of the statistical test for each spectral period and for every classes pair. In all panels, many couples of classes present statistically equivalent mean amplifications (red squares); we actually have only one case
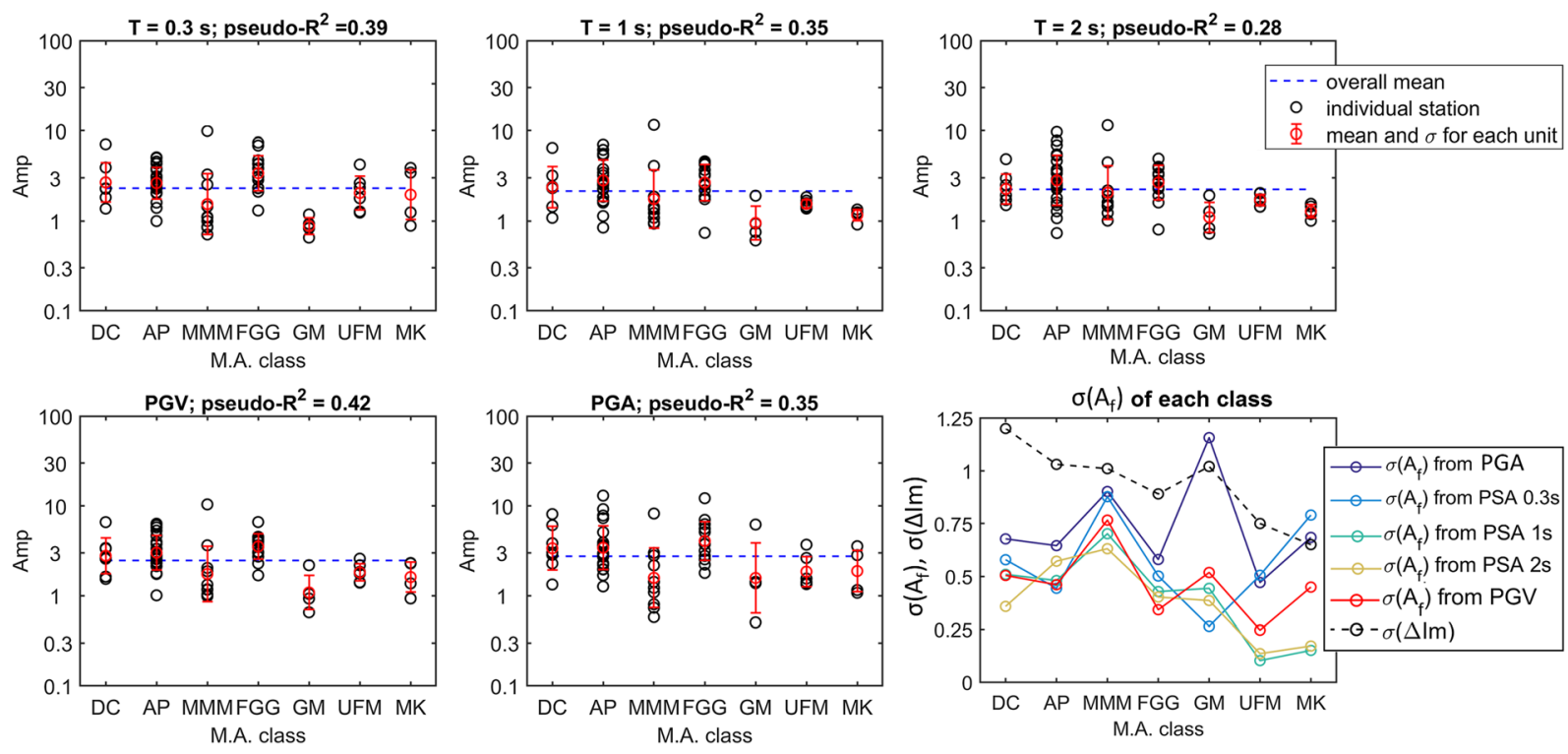

Fig. 10 From left to right, top to bottom: distribution of the Amp factors at spectral period $0.3 \mathrm{~s}, 1.0 \mathrm{~s}, 2.0 \mathrm{~s}, \mathrm{PGV}$, and PGA (ordinates, in $\log _{10}$ scale) for each of the macroseismic amplification map classes hosting at least 4 seismic stations (abscissae; DC, debris cones; AP, alluvial plains; MMM, moraines on midland molasses; FGG, fluvioglacial/glaciolacustrine gravels; GM, gneiss micaschist; UFM, upper freshwater molasses; MK, Muschelkalk
Jura chain (Mesozoic)). The Amp from individual stations are in black circles; the classes' average values and standard deviations are in red. Lower right corner: standard deviations of the empirically derived $A f$ for each considered geological class, translated into $A$ funits (coloured continuous lines), collated with the $\sigma$ for the $\Delta I m$ (black dashed line, from Fäh et al. 2011) 
Table 5 Standard deviations $\sigma$ of the empirical amplification factors for each geological class, translated into $A f$ units, as well as $\sigma$ for the $\Delta I m$ (from Fäh et al. 2011). The acronyms for the considered classes are the same of Fig. 10

\begin{tabular}{|c|c|c|c|c|c|c|c|c|}
\hline \multicolumn{2}{|l|}{ Geological class } & \multirow{2}{*}{$\frac{\mathrm{DC}}{0.68}$} & \multirow{2}{*}{$\frac{\mathrm{AP}}{0.65}$} & \multirow{2}{*}{$\frac{\mathrm{MMM}}{0.90}$} & \multirow{2}{*}{$\frac{\mathrm{FGG}}{0.58}$} & \multirow{2}{*}{$\frac{\mathrm{GM}}{1.16}$} & \multirow{2}{*}{$\frac{\text { UFM }}{0.47}$} & \multirow{2}{*}{$\frac{\mathrm{MK}}{0.68}$} \\
\hline PGA & $\sigma(A f)$ & & & & & & & \\
\hline PSA, $T=0.3 \mathrm{~s}$ & & 0.58 & 0.44 & 0.88 & 0.50 & 0.26 & 0.51 & 0.79 \\
\hline PSA, $T=1 \mathrm{~s}$ & & 0.51 & 0.48 & 0.70 & 0.43 & 0.44 & 0.10 & 0.15 \\
\hline PSA, $T=2 \mathrm{~s}$ & & 0.80 & 0.69 & 0.67 & 0.60 & 0.68 & 0.50 & 0.43 \\
\hline PGV & & 0.50 & 0.46 & 0.77 & 0.34 & 0.52 & 0.25 & 0.45 \\
\hline Macroseismic obs & $\sigma(\Delta I m)$ & 1.20 & 1.03 & 1.01 & 0.89 & 1.02 & 0.75 & 0.65 \\
\hline
\end{tabular}

(Gneiss Micaschist, period $0.3 \mathrm{~s}$ ) where a subgroup succeeds in having an average amplification value not equivalent to any of the other classes. PGV has the highest number of class pairs with not equivalent means (12 out of 21 possible unordered couples), while PGA has the lowest (7 out of 21); as for PSA amplification factors, the not equivalent pairs amount to 11 .

\section{Discussion and concluding remarks}

In this work, we collate macroseismic intensity observations in terms of $\Delta I m$ (local response expressed in macroseismic amplification) with experimental geophysical data, highlighting a good correspondence. The $\Delta I m$ in the current Swiss macroseismic amplification map refer to another S-wave velocity reference than the one $\left(V_{S, 30}=1105 \mathrm{~m} / \mathrm{s}\right.$; Poggi et al. 2011) used in the calculation of the empirical amplification functions (Edwards et al. 2013) and for the Swiss seismic hazard ( $V_{S, 30}$ of $1105 \mathrm{~m} / \mathrm{s}$; Wiemer et al. 2016). Fäh et al. (2011) suggested a constant correction term of about $+1 / 2$ intensity units (namely 0.47 ), accounting for the necessary adjustment of the macroseismic amplification map to the Swiss reference rock. In this study, this correction value $d \Delta f$ was assessed by comparing empirical amplification observed at seismic stations and converted to amplification in intensity $(A f)$, with the values of the macroseismic amplification map at the instrumented sites $(\Delta \mathrm{Im})$.

Most of the observed $\Delta I m$ used to derive the macroseismic amplification map refer to lower-grade intensities, below intensity VI (Fäh et al. 2011). At these intensities, no damage occurs, and intensity is best correlated with PGV and PGA (e.g. Omine et al. 2008). Therefore, observed $A f$ derived from PGV and PGA might be preferred when compared to $\Delta I m$. The $d \Delta f$ due to the different soil/rock references is therefore measured best from PGV $(0.42,0.37$; from Figs. 3 and 4) and PGA (0.56, 0.52; from Figs. 3 and 4). These values are in agreement with the constant correction of 0.47 or $1 / 2$ (intensity units) suggested by Fäh et al. (2011). When we consider intensity grades in which damage to buildings is described (VI and above), PGA should preferably be weighted less than PGV and SA at the period of the buildings, to correct for the difference in reference soil/rock conditions. For longer periods (high-rise buildings), the influence of the deeper structure could be more relevant. The $d \Delta f$ therefore becomes smaller with increasing periods. Moreover, it appears that the deeper structure is less reflected in the amplification derived from IDP. For the Swiss building stock, it is suggested that $\mathrm{SA}$ at $0.3 \mathrm{~s}(0.32,0.31$; from Figs. 3 and 4$)$ together with PGV $(0.42,0.37$; from Figs. 3 and 4) might be the best selection to correct for the difference in reference soil/rock conditions.

The reference soil conditions of the macroseismic amplification map have been assessed using different techniques. The IDP were subdivided in each geological/tectonic unit as in the macroseismic amplification map and plotted together with the average $V_{S, 30}$ values (Fig. 5). This analysis reveals that most of the IDP have a $V_{S, 30}$ in the range $258-687 \mathrm{~m} / \mathrm{s}$ with an average value of $472 \pm 214 \mathrm{~m} / \mathrm{s}$. This suggests that the map is derived using mostly observations from soil classes B and C. For this reason, the $d \Delta f$ were also plotted versus building code SIA-261 (2014) soil classification, confirming that average $d \Delta f$ for soil classes $\mathrm{B}$ and $\mathrm{C}$ are the closest to those found in this study. This corresponds to a $V_{S, 30}$ value in the range of about $400-600 \mathrm{~m} / \mathrm{s}$ for the soil reference condition of the macroseismic amplification map. It was shown that the macroseismic amplification map has the tendency to provide too high values for non-weathered rock materials and too low values for the soft sediments in soil class D. 

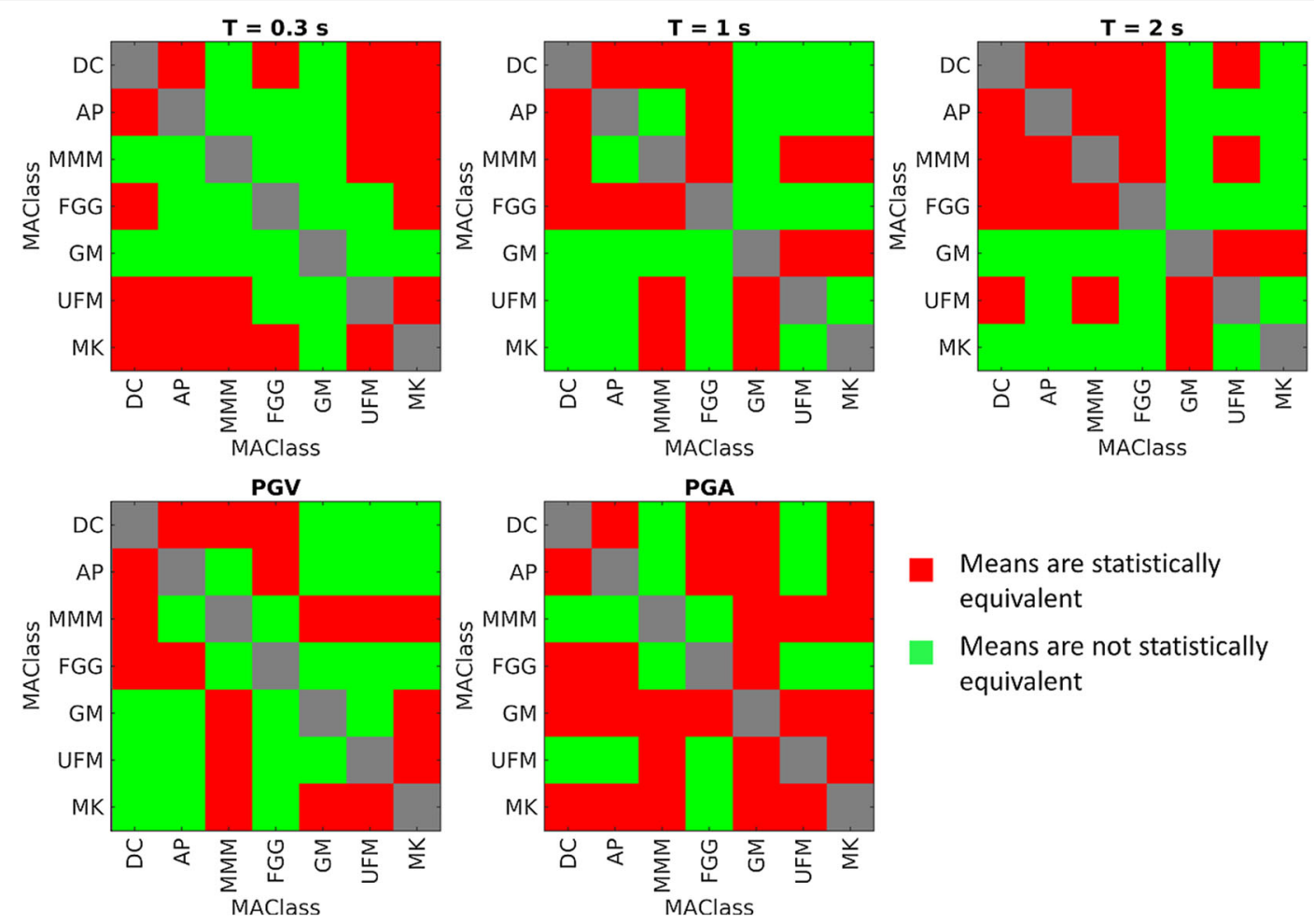
Means are statistically equivalent
Means are not statistically equivalent

Fig. 11 Matrices representing the outcome of the Welch $t$ test to determine whether two macroseismic amplification classes (MAClass) have statistically equivalent (red squares) or not

The $V_{S, 30}$ values obtained with the previous methods are slightly lower than $640 \pm 58 \mathrm{~m} / \mathrm{s}$ derived from the relationships between $A f$ and $V_{S, 30}$ site proxy. Macroseismic amplification factors $A f$, derived from the measured empirical amplifications, were correlated in this approach with site response proxies, such as the quarter-wavelength velocity $\left(V_{\mathrm{QWL}}\right)$ at $0.3 \mathrm{~s}, 0.5 \mathrm{~s}$, and $1.0 \mathrm{~s}$, and travel time averaged velocities $\left(V_{S, Z}\right)$. The results point out that the best correlations are obtained for SA at $0.3 \mathrm{~s}, \mathrm{PGV}$, and PGA. Using these relationships and the obtained $\mathrm{d} \Delta \mathrm{f}$, it was possible to retrieve an estimate of the soil reference condition proxies for the macroseismic amplification map in terms of $V_{S, Z}$. In particular, the $V_{S, 30}$ value of the reference soil is about $640 \pm 58 \mathrm{~m} / \mathrm{s}$. Using these different methods, we can also define a lower bound of $450 \mathrm{~m} / \mathrm{s}$ and an upper bound of $700 \mathrm{~m} / \mathrm{s}$ for $V_{S, 30}$ of the macroseismic amplification map soil reference. Uncertainties are high due to the properties of macroseismic intensity, as shown in Figs. 3, 5, and 10.

Finally, we assessed the statistical significance of the geological/tectonic classification of the macroseismic equivalent (green squares) mean amplification factors. The acronyms for the considered classes are the same of Fig. 10

amplification map with respect to the empirical amplification data at instrumented sites. This analysis highlights that presently, it is not possible to evaluate systematically the significance of the geological/tectonic units in the macroseismic amplification map, basing the analysis on site response data collected at the available instrumented sites. The number of stations is in fact insufficient, and these are not evenly distributed among the various units. However, the analysis was carried out on a limited number of soil classes (7) in the macroseismic amplification map, evidencing that these classes host stations that generally show an internally consistent site response pattern; however, not necessarily all macroseismic units differ significantly in their average behaviour. This fact opens up to the possibility of reviewing the macroseismic amplification map by merging classes with similar behaviour or by defining a new classification scheme based also on other proxies besides geology and tectonics.

Acknowledgements The authors thank the Editors Prof. Dario Alberallo and Dr. Franco Pettenati and an anonymous reviewer, whose comments have greatly helped improve the article. 
Funding Open access funding provided by Swiss Federal Institute of Technology Zurich. This work was made in the frame of the Risk Model Switzerland project financed by contributions from the Swiss Federal Office for the Environment (FOEN), Swiss Federal Office for Civil Protection (FOCP), and Eidgenössische Technische Hochschule Zürich (ETHZ).

Open Access This article is licensed under a Creative Commons Attribution 4.0 International License, which permits use, sharing, adaptation, distribution and reproduction in any medium or format, as long as you give appropriate credit to the original author(s) and the source, provide a link to the Creative Commons licence, and indicate if changes were made. The images or other third party material in this article are included in the article's Creative Commons licence, unless indicated otherwise in a credit line to the material. If material is not included in the article's Creative Commons licence and your intended use is not permitted by statutory regulation or exceeds the permitted use, you will need to obtain permission directly from the copyright holder. To view a copy of this licence, visit http://creativecommons.org/licenses/by/4.0/.

\section{References}

Bergamo P, Hammer C, and Fäh D. (2019) SERA WP7/NA5-task 7.4 towards improvement of site characterization indicators. Seismology and Earthquake Engineering Research Infrastructure Alliance for Europe (SERA) project, Deliverable D7.4. (http://www.sera-eu.org/en/Dissemination/deliverables/, last retrieved on 26.06.2020)

Boore DM (2003) 85.13 SMSIM: stochastic method simulation of ground motion from earthquakes. In: International Geophysics. pp 1631-1632

Carlino S, Cubellis E, Marturano A (2010) The catastrophic 1883 earthquake at the island of Ischia (Southern Italy): macroseismic data and the role of geological conditions. Nat Hazards 52:231-247. https://doi.org/10.1007/s11069009-9367-2

Cauzzi C, Edwards B, Fäh D, Clinton J, Wiemer S, Kästli P, Cua G, Giardini D (2015) New predictive equations and site amplification estimates for the next-generation Swiss ShakeMaps. Geophys J Int 200:421-438. https://doi. org/10.1093/gji/ggu404

Edwards B, Fäh D (2013) Measurements of stress parameter and site attenuation from recordings of moderate to large earthquakes in Europe and the Middle East. Geophys J Int 194: 1190-1202. https://doi.org/10.1093/gji/ggt158

Edwards B, Michel C, Poggi V, Fäh D (2013) Determination of site amplification from regional seismicity: application to the Swiss national seismic networks. Seismol Res Lett 84:611621. https://doi.org/10.1785/0220120176

Faenza L, Michelini A (2010) Regression analysis of MCS intensity and ground motion parameters in Italy and its application in ShakeMap. Geophys J Int 180:1138-1152. https://doi. org/10.1111/j.1365-246X.2009.04467.x

Faenza L, Michelini A (2011) Regression analysis of MCS intensity and ground motion spectral accelerations (SAs) in Italy.
Geophys J Int 186:1415-1430. https://doi.org/10.1111 j.1365-246X.2011.05125.x

Fäh D, Fritsche S, Poggi V, et al (2009) Determination of site information for seismic stations in Switzerland, Swiss Seismological Service technical report: SED/PRP/R/004/ 20090831

Fäh D, Giardini D, Kästli P, et al (2011) ECOS-09 earthquake catalogue of Switzerland release 2011. Report and database. $\mathrm{Sed} / \mathrm{Ecos} / \mathrm{R} / 001 / 20110417$

Field EH, Jacob KH (1995) A comparison and test of various site response estimation techniques, including three that are not reference site dependent. Bull Seismol Soc Am 85:11271143

Hobiger M, Fäh D, Scherrer C, et al (2017) The renewal project of the Swiss Strong Motion Network (SSMNet). In: Proceedings of the 16th World Conference on Earthquake engineering (16WCEE). Santiago de Chile, Chile

Kaestli P, Fäh D (2006) Rapid estimation of macroseismic effects and Shakemaps using macroseismic data. In: 1st European Conf. Earthquake Engineering and Seismology. Geneva, Switzerland, p 1535

Kaka SLI, Atkinson GM (2004) Relationships between instrumental ground-motion parameters and modified Mercalli intensity in eastern North America. Bull Seismol Soc Am 94:17281736. https://doi.org/10.1785/012003228

Michel C, Edwards B, Poggi V, Burjanek J, Roten D, Cauzzi C, Fah D (2014) Assessment of site effects in Alpine regions through systematic site characterization of seismic stations. Bull Seismol Soc Am 104:2809-2826. https://doi. org/10.1785/0120140097

Michel C, Fäh D, Edwards B, Cauzzi C (2017) Site amplification at the city scale in Basel (Switzerland) from geophysical site characterization and spectral modelling of recorded earthquakes. Phys Chem Earth, Parts A/B/C 98:27-40. https://doi.org/10.1016/j.pce.2016.07.005

Murphy BP, Chakravarti IM, Laha RG, Roy J (1968) Handbook of methods of applied statistics. Vol. I: Techniques of computation, descriptive methods and statistical inference. Appl Stat 17:293. https://doi.org/10.2307/2985652

Musson RMW, Grünthal G, Stucchi M (2010) The comparison of macroseismic intensity scales. J Seismol 14:413-428. https://doi.org/10.1007/s10950-009-9172-0

Omine H, Hayashi T, Yashiro H, Fukushima S (2008) Seismic risk analysis method using both PGA and PGV. In: Proceeding of the 14th World Conference on Earthquake Engineering. Beijing, China

Panzera F, D'Amico S, Lombardo G, Longo E (2016) Evaluation of building fundamental periods and effects of local geology on ground motion parameters in the Siracusa area, Italy. J Seismol 20:1001-1019. https://doi.org/10.1007/s10950-0169577-5

Panzera F, Lombardo G, Imposa S, Grassi S, Gresta S, Catalano S, Romagnoli G, Tortorici G, Patti F, di Maio E (2018) Correlation between earthquake damage and seismic site effects: the study case of Lentini and Carlentini, Italy. Eng Geol 240:149-162. https://doi.org/10.1016/j.enggeo.2018.04.014

Pettenati F, Sirovich L (2007) Validation of intensity-based source inversion of three destructive Californian earthquakes. Bull Seismol Soc Am. 97:1587-1606

Pettenati F, Sirovich L, Sandron D (2018) Modern techniques of treating damage patterns (intensity) to retrieve information on 
the 6 May 1976 M 6.4 earthquake. Boll Geof Teor 59(4): 445-462. https://doi.org/10.4430/bgta0250

Poggi V, Burjánek J, Michel C, Fäh D (2017) Seismic siteresponse characterization of high-velocity sites using advanced geophysical techniques: application to the NAGRANet. Geophys J Int 210:645-659. https://doi.org/10.1093 /gji/ggx192

Poggi V, Edwards B, Fäh D (2011) Derivation of a reference shear-wave velocity model from empirical site amplification. Bull Seismol Soc Am 101:258-274. https://doi.org/10.1785 /0120100060

Roten D, Fäh D, Olsen KB, Giardini D (2008) A comparison of observed and simulated site response in the Rhône valley. Geophys J Int 173:958-978. https://doi.org/10.1111/j.1365246X.2008.03774.X

Sbarra P, De Rubeis V, Di Luzio E et al (2012) Macroseismic effects highlight site response in Rome and its geological signature. Nat Hazards 62:425-443. https://doi.org/10.1007/s11069-012$0085-9$

SIA-261 (2014). SIA 261 Azioni sulle strutture portanti. Compiled by: SIA (Società svizzera degli ingegneri e degli architetti) Copyright (C) 2014 by SIA Zurich

Sousa ML, Oliveira CS (1996) Hazard mapping based on macroseismic data considering the influence of geological conditions. Nat Hazards 14:207-225
Swisstopo (2005) Geological map of Switzerland 1:500 000. Compiled by: Geological Institute, University of Bern, and Federal Office for Water und Geology. ISBN number: 3906723-39-9

Swisstopo (2020) The large-scale topographic landscape model of Switzerland swissTLM3D. https://shop.swisstopo.admin. ch/it/products/landscape/tlm3D

Wald DJ, Worden BC, Lin K, Pankow K (2005) ShakeMap manual: technical manual, user's guide, and software guide. U. S. Geological Survey, Techniques and Methods 12-A1, pp. 132. https://doi.org/10.3133/tm12A1

Welch BL (1947) The generalization of 'student's' problem when several different population variances are involved. Biometrika 34:28-35. https://doi.org/10.1093/biomet/34.12.28

Wiemer S, Danciu L, Edwards B, et al (2016) Seismic hazard model 2015 for Switzerland (SUlhaz2015)

Wu Y-M (2003) Relationship between peak ground acceleration, peak ground velocity, and intensity in Taiwan. Bull Seismol Soc Am 93:386-396. https://doi.org/10.1785/0120020097

Publisher's note Springer Nature remains neutral with regard to jurisdictional claims in published maps and institutional affiliations. 